\title{
ESTUDO DE USUÁRIOS E MODELOS DE BUSCA DA INFORMAÇÃO
}

\section{USER STUDIES AND INFORMATION SEEKING MODELS \\ Francisco Carlos Paletta ${ }^{1}$, Bárbara Pelissaro ${ }^{2}$}

RESUMO: A Sociedade do Conhecimento se configura por trazer como características intrínsecas à sua definição a associação das dinâmicas das ações voltadas à organização da informação com os aparatos tecnológicos da comunicação, ganhando força na produção do conhecimento. Ter e fornecer acesso a essas informações condiz com o desenvolvimento econômico de cada país e seus interesses sociais, funcionando como agente determinante de desenvolvimento sustentável. O que então poderia servir para unir nações e conhecimento tem servido cada vez mais para consolidar uma separação de caráter estritamente financeiro. Daí a importância de investir no uso das tecnologias e nos profissionais da informação, área que representa status avançado na evolução da sociedade e, na mesma medida, investir em estudos voltados à informação e à gestão do conhecimento, para entender as diferentes necessidades de quem anseia por informação, as dificuldades de quem a procura e os caminhos a trilhar para facilitar ou tornar menos árdua a busca pelo conhecimento.

Palavras-Chave: Estudo de usuário. Modelos de busca da informação. Ciência da informação. Biblioteconomia. Sociedade do conhecimento

ABSTRACT: The Knowledge Society is based on having features intrinsic to its own definition the combination with the dynamics of actions for the organization of information with technological devices of communication, gaining strength in the production of the knowledge. Having and providing the access to such information is in accordance with the economic development of each country as its social interests, working as a crucial role of sustainable development agent. What could contribute as a basis for bringing knowledge and nations together, in the reality it has been used more and more as a reason to strengthen the separation strictly financial nature. Then, it is clear the importance of investments in the employment of technologies and information professionals, area which represents a valuable status in the development of the society and also, at the same level, continuous investments in studies on information and knowledge management in order to understand different needs of those looking for information and their difficulties and the ways to make it easier the hard search for knowledge.

KEYWORDS: User studies. Information seeking model. Information sciences. Library science. Knowledge society.

\footnotetext{
${ }^{1}$ Professor e Pesquisador da Universidade de São Paulo, Escola de Comunicações e Artes, Departamento de Biblioteconomia e Documentação.

${ }^{2}$ Escola de Comunicações e Artes - Universidade de São Paulo

Submetido em: 02/03/2014 - Aceito em: 24/09/2014
}

(C) Rev. digit. bibliotecon. cienc. inf.

Campinas, $\mathrm{SP}$

v.13

n.1

p.120-137

jan/abr. 2015

ISSN 1678-765X 


\section{IINTRODUÇÃO}

Os ambientes informacionais digitais, a partir dos quais estabelecemos um processo de produção de conhecimento de forma colaborativa, tem ganhado importância e relevância com a incorporação e o uso das Tecnologias de Informação e Comunicação (TICs), como no caso das bibliotecas e repositórios digitais que armazenam, preservam, disseminam e permitem o acesso, a apropriação e o uso da informação, gerando novos conhecimentos.

Adaptamo-nos rapidamente às transformações tecnológicas que, sem percebermos, são inseridas no nosso dia a dia. A nova era da informação, além de mudar a vida particular de cada um, muda também os valores sociais e econômicos da sociedade. Essa transformação tem origem em três fenômenos: a convergência da base tecnológica (processamento digital), a dinâmica da indústria (queda de preço, que populariza o uso das máquinas) e o crescimento da Internet (que viabiliza o acesso à informação).

A sociedade da informação reestrutura e reorganiza a sociedade e a economia, sendo um fenômeno global com poder de transformar a sociedade, a economia e a política, pois o tipo de informação disponível interfere diretamente em suas estruturas, tornando (ou não) as distâncias menores, a economia mais atraente e a disparidade social menor (TAKAHASHI, 2000, p. 5).

Os países se adequam de acordo com seus contextos, condições e tecnologias, sendo os economicamente mais desenvolvidos já adeptos a políticas e iniciativas voltadas para a construção dessa sociedade, que deve ser o resultado de uma parceria em níveis local, nacional e internacional. Ao Brasil cabe acelerar e aprimorar um programa nacional para esse fim. Para tanto, nos anos 1990, realizou-se no país a expansão das plataformas da Internet e a criação da Agência Nacional de Telecomunicações (Anatel), dando impulso às atividades on-line e configurando-se como responsável por metade do mercado latinoamericano, posição favorável para o seu desenvolvimento nessa modalidade. Seu sucesso, entretanto, depende de investimentos em tecnologia, educação e normas governamentais e a participação de pessoas e organizações.

O País dispõe, pois, dos elementos essenciais para a condução de uma iniciativa nacional rumo à sociedade da informação. $\mathrm{E}$ a emergência do novo paradigma constitui, para o Brasil, oportunidade sem precedentes de prestar significativa contribuição para resgatar a sua dívida social, alavancar o desenvolvimento e manter uma posição de competitividade econômica no cenário internacional. (TAKAHASHI, 2000, p. 5). 
Inovação é uma vantagem competitiva nessa sociedade, cuja estrutura de trabalho é alterada. A rapidez da difusão de informação traz consigo a constante necessidade de modernização, logo, a aplicação de conhecimento e inteligência nessa dinâmica. No caso brasileiro, cabe ao poder público e à iniciativa privada a gestão do uso adequado das tecnologias e a geração de mecanismos de incentivo e financiamentos para o seu desenvolvimento.

É essencial, portanto, ampliar a empregabilidade dos trabalhadores, por meio de aprendizado continuado e do desenvolvimento de novas habilidades e competências, sobretudo quanto ao conhecimento das tecnologias de informação e comunicação.

[...] o País deve ainda manter uma política consistente de investimento em recursos humanos, de modernização da infraestrutura científicotecnológica de apoio à integração universidade-empresa e de ativa cooperação internacional. (TAKAHASHI, 2000, p. 7/9).

A informação deve ser transformada em conhecimento, sendo a educação continuada o elemento base para que isso ocorra. Portanto, a capacitação pedagógica e tecnológica de educadores deve andar em paralelo ao desenvolvimento de conteúdo local, assim como à preservação da identidade e prioridades nacionais.

\section{ORGANIZAÇÃO DA INFORMAÇÃo}

A Ciência da Informação tem como objetivo a organização da informação, assim como seu acesso e processo de disseminação por meio das diferentes tecnologias aplicadas às plataformas de informação e comunicação, voltada à prática científica e profissional no âmbito social e individual. Por isso a necessidade de estar inserida no campo da Teoria da Informação (estrutura) e na Teoria da Comunicação (mensagem).

A informação é a representação simbólica de um fato ou uma ideia capaz (ou não) de alterar o conhecimento, cujo valor e definição só podem ocorrem de acordo com o contexto em que está inserida, portanto, ela pode ser tomada em três diferentes usos:

- Como processo: quando, no ato de informar, ao saber de algo o conhecimento é modificado.

- Como conhecimento: quando se obtém uma informação que transforma o conhecimento, reduzindo-o ou aumentando-o.

\begin{tabular}{|l|l|l|l|l|l|l} 
(C) Rev. digit. bibliotecon. cienc. inf. & Campinas, SP & v.13 & n.1 & p.120-137 & jan/abr. 2015 & ISSN 1678-765X \\
\hline
\end{tabular}


- Como coisa: quando a informação é apenas um dado.

Há também diferentes episódios que levam o usuário a buscar informação, que influenciam no modo como esta é tratada e que mudam constantemente:

- Cognitivo: quando há uma interação usuário-informação, pois esta é obtida cognitivamente e interpretada.

- Situacional: quando uma situação cria no usuário a necessidade de busca por informação.

- Emocional: quando o usuário interage com as intenções e motivações associadas a outros sentimentos relacionados à busca pela informação, como satisfação ou frustração.

À medida que existe uma reação que afeta a relação do usuário com a informação, consequentemente, o sistema de busca é afetado, pois os modos de busca podem ser alterados numa constante tentativa de recuperação daquilo que se procura.

O advento da Segunda Guerra Mundial e o seu desenvolvimento tecnológico trouxeram novas necessidades e novos problemas para armazenar e recuperar informação, sendo a Ciência da Informação um dos meios bem-sucedidos para solucionar essa questão, e a representação, a busca e os sistemas de operação da informação os pontos-chave relevantes até hoje nesse campo de estudo. Advindos dessa ciência, a organização e a representação do conhecimento é o que torna viável gerar instrumentos para a recuperação da informação estando devidamente registrada fisicamente, no caráter de documento -, formando um ciclo: o conhecimento organizado (socializado) é registrado como informação passível de ser recuperada (disponível) para gerar novo conhecimento, pois a informação necessita de um suporte para ser transmitida (impresso, digital, sonoro, visual) e utiliza os sistemas de linguagem para ser decodificada (linguagem documentária). Ela é produzida por uma pessoa que gera conhecimento para outra pessoa.

A fragmentação e a constante transformação da dinâmica do conhecimento estão à mercê dos processos e políticas de atualização da Ciência da Informação, o que torna muito difícil ao profissional da área acompanhar eficientemente todas essas modificações. A produção de representação de recursos informacionais, atividade relacionada à Organização da Informação, é um facilitador da medição qualificativa desse fenômeno, pois expõe o 
usuário, as suas necessidades e as informações potencialmente relevantes em sua busca dentro de um determinado sistema. (SQUIRRA, 2005).

A representação assume diversos significados, de acordo com o campo que a detém. De modo geral, há um consenso de que ela aponta para uma relação ao objeto a que se refere, mas tem no emissor, no objeto em si e no receptor, noções de valores diferentes, pois a cada um cabe uma interpretação de mundo diferente. "A representação então relaciona o objeto que ela representa com a mente que o percebe.” (MARCONDES, 2001 apud GARCIA, 2007, p. 37). A representação também ocorre em forma de ícones ou imagens; e sua compreensão ocorre por meio de regras que acentuam ou suprimem algumas características do objeto / documento para que o ele seja identificável.

As representações podem ser divididas em três tipos de fontes: são primárias as fontes originais, as representações de seus autores, no âmbito da expressão; estas se tornam secundárias ao serem transformadas em registros de conhecimento por meio de tratamento documental; e passam a ser terciárias ao tornarem-se passíveis de recuperação e recuperadas em sistemas documentais.

Entretanto, como aponta Buckland (1991 apud GARCIA, 2007, p. 34), é importante salientar algumas características das representações da informação na Ciência da Informação (embora se insira em diferentes ciências, como: Semiótica, Semiologia, Linguística, Ciência da Computação e outras):

- elas são, de algum modo, incompletas, na medida em que refletem apenas um ponto de vista, o que faz com que algo do original se perca;

- sua finalidade é facilitar o armazenamento, a compreensão e a busca;

- exercem o papel de réplica ou substituto do documento original;

- seus detalhes adicionais sempre dizem respeito apenas ao documento referenciado;

- podem ser repetidas; e

- são breves.

São atores envolvidos na atividade de organização da informação os autores e os profissionais da informação, pois ela compreende, para a sua execução, tanto o

\begin{tabular}{l|l|l|l|l|l|l|l}
\hline (C) Rev. digit. bibliotecon. cienc. inf. & Campinas, SP & v.13 & n.1 & p.120-137 & jan/abr. 2015 & ISSN 1678-765X \\
\hline
\end{tabular}


conhecimento temático (tratamento do conteúdo) quanto o teórico (tratamento físico, descritivo). O primeiro visa à recuperação do que está expresso no texto, enquanto o segundo foca-se na acessibilidade ao documento.

Segundo Rowley (2002 apud GARCIA, 2007, p. 40-41), todas as etapas se dão em quatro processos:

- Representação descritiva.

- Representação temática.

- Registro de metadados.

- Armazenamento e processo de recuperação.

A interação do usuário com o sistema para o reconhecimento do produto final é o que caracteriza o comportamento de busca de informação.

$\mathrm{O}$ ambiente informacional deve atender às diversas necessidades de diferentes usuários e, para tal, prover múltiplas formas de representação. Ele deve prever também a economia de energia nessa busca, para que o resultado final da recuperação da informação seja feliz. Por isso, a representação deve sempre estar focada no usuário e não se caracterizar como uma simples resposta à demanda e à entrega de informação, mas à eficácia envolvida em todo o processo.

Embora o campo da recuperação da informação ${ }^{3}$ tenha crescido nos últimos anos, os usuários ainda têm dificuldade em utilizar os sistemas de busca, realizando consultas inadequadas em decorrência da pouca interatividade que tais sistemas oferecem, o que acarreta em consumo de tempo e intolerância em investigar mais detalhadamente os resultados recuperados. Com foco nessa inter-relação, as pesquisas em information seeking ${ }^{4}$ pensam meios de tornar a busca pela informação mais fácil, com melhor desempenho e de modo intuitivo.

Entretanto, construir sistemas de busca não é uma tarefa simples, pois, além de competência na área de recuperação da informação, é necessário ter conhecimento sobre as

\footnotetext{
${ }^{3}$ Área de pesquisa que se preocupa com a estrutura, análise, organização, armazenamento, recuperação e busca de informação (SALTON, 1968 apud BEPPLER, 2008).

${ }^{4} \mathrm{O}$ termo sofre diferentes definições por diversos autores. No geral, eles concordam com a acepção de que se refere à tomada de decisão de uma pessoa, à busca de informação para suprir uma necessidade ou a falta de conhecimento em determinado assunto quando esta é identificada.

\begin{tabular}{|l|l|l|l|l|l|l} 
(C) Rev. digit. bibliotecon. cienc. inf. & Campinas, SP & v.13 & n.1 & p.120-137 & jan/abr. 2015 & ISSN 1678-765X \\
\hline
\end{tabular}
}


informações da área do domínio e considerar o comportamento humano dinâmico no processo de busca. A engenharia do conhecimento visa à construção de mecanismos que tornem mais eficientes a manipulação e o gerenciamento do conhecimento, com ferramentas que permitam que ele possa ser explorado. O que as fontes de informação não estão aptas a processar é a dinamicidade do usuário, que a cada interação vê surgir novas ideias e novas necessidades de consulta.

A cada estágio de interação os usuários não estão apenas alterando os termos de uma consulta, eles estão em um processo de mudança contínua tanto das ações a serem tomadas, baseadas em um determinado resultado, quanto da necessidade em seu conjunto. (BEPPLER, 2008, p. 8).

\section{RECUPERAÇÃO DA INFORMAÇÃ̃o}

Segundo Lancaster (1993, p. 202 apud LOPES, 2002, p. 60), a evolução histórica dos sistemas de recuperação da informação apresenta duas linhas de desenvolvimento: a primeira tem base nos sistemas das instituições National Library of Medicine (NLM), Department of Defense (DOD) e National Aeronautics and Space Administration (Nasa), que utilizavam tesauros específicos de áreas temáticas para indexação; e a segunda no campo do Direito, que envolvia a criação de bases de dados com os textos completos das leis. Ambas exigiam planejamento acurado da busca, respeitando os resultados esperados pelos usuários.

A Recuperação da Informação está no cerne da Ciência da Informação. Ela objetiva, como o próprio nome sugere, entender os processos de recuperação da informação para aprimorar e facilitar os sistemas de busca, promovendo melhores resultados para os usuários.

Há duas linhas de pesquisa nessa área: uma focada na abordagem computacional, baseada em softwares (com interface de busca, banco de dados e mecanismos de busca); e outra, centrada no usuário e em seu comportamento de busca, baseada na recuperação e na qualidade / confiabilidade da informação. A diferença crucial entre ambas as perspectivas é que a primeira entende que o sistema recupera a informação, enquanto plataforma de busca, e a segunda entende que é o usuário quem a recupera, pois a informação consiste na relação que ocorre entre sujeito de busca e objeto buscado. A segunda linha amplia os limites da recuperação da informação, uma vez que incorpora o caráter humano aos estudos.

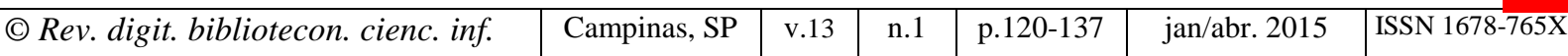


Buscar informação compreende uma estratégia de busca com técnicas que tornam possíveis a conexão entre uma pergunta formulada e uma base de dados, ou num esquema simplificado, como mostra o quadro 1 :

Quadro 1 - Estratégia de Busca da Informação

\begin{tabular}{|c|c|c|}
\hline Representação & Função de comparação & Questão \\
\hline $\begin{array}{c}\text { Informação potencial em } \\
\text { linguagem documentária como } \\
\text { registro de metadados }\end{array}$ & $\begin{array}{c}\text { Comparativo da representação da } \\
\text { questão com a representação dos } \\
\text { documentos recuperados }\end{array}$ & $\begin{array}{c}\text { Requerimento para informação } \\
\text { em linguagem natural / de }\end{array}$ \\
interrogação
\end{tabular}

Fonte: Ingwersen (2002 apud GARCIA, 2007, p. 48).

O problema reside na localização da informação correta, pois no resultado da busca são gerados documentos e partes de documentos com diferentes níveis de relevância e significado referentes à informação buscada. Daí o papel crucial do profissional da informação, como aquele que possui discernimento para avaliar a pertinência do que é útil em determinado contexto, o que lhe exige maior conhecimento da comunidade usuária com a qual trabalha.

No meio dos extremos usuário-sistema, a interface age como auxiliar ao profissional da informação, intermediando os dois polos e propiciando a comunicação. É nessa interação que a Recuperação e a Organização da Informação se intersectam, pois a primeira contribui com subsídios para o estudo do usuário, indicando seu comportamento no processo de busca; enquanto a segunda contribui com o desenvolvimento de interfaces que reduzem a complexidade no processo de busca.

A constante evolução da tecnologia digital tem mudado o comportamento da busca da informação, da postura do usuário frente aos novos sistemas e dos canais de informação. Embora as ferramentas da web aumentem o aparato de possibilidades de armazenamento, elas exigem que todos os envolvidos no assunto tenham competência para operacionalizálas, o que afeta diretamente os processos de representação e organização, armazenamento e representação e busca da informação.

As linguagens documentárias são as responsáveis pela construção das interfaces (softwares) que conectam as informações dos documentos (inseridos num sistema) e o usuário (em seu contexto) num sistema de hipertexto. Houve um tempo em que se pensava que a informática era apenas uma ferramenta de cálculo, sem potencialidades como tecnologia intelectual. O avanço tecnológico, entretanto, mudou essa visão e permitiu que ela fosse muito além disso. 
O hipertexto tem similaridade com os processos do pensamento e da memória humana, na medida em que funciona como uma contiguidade, embora não sequencial, de associações que se ligam numa organização própria - ou não organização, ou não linear - e que necessitam de armazenamento. Ele traz portas que abrem caminhos dentro do documento. Paralelamente ao texto impresso, este apresenta estrutura formal linear, com palavras que formam frases que formam parágrafos e assim por diante, enquanto aquele traz informações armazenadas em cada célula de sua composição, podendo levar a diferentes entradas, como gráficos, imagens, sons e outras. Além disso, essa dinâmica ocorre por meio eletrônico e pode sempre ser alterada, o que muda completamente a relação e a interação que se tem com o texto.

Também neste caso é imprescindível concentrar-se no usuário e seu contexto para o melhor desenvolvimento do hipertexto, pois somente assim é possível reduzir seu esforço no momento da busca e evitar que ele se perca numa infinidade de links e esteja mais bem orientado na navegação, otimizando a utilização do conhecimento.

"Sem dúvida, é todo o contexto que define as necessidades de informação de um indivíduo, pois este necessita executar determinadas tarefas nos diferentes ambientes e momentos em que atua para atingir seus objetivos" (GARCIA, 2007), entretanto, a grande dificuldade está em como se fazer isso.

\section{MODELOS DE BUSCA E COMPORTAMENTO INFORMACIONAL}

A Biblioteconomia e Documentação está a serviço da informação e, para tal, utiliza meios para sua organização e recuperação. No que diz respeito à web, as antologias ou taxonomias virtuais são modelos de organização, pois funcionam como ferramentas para classificação. É preciso haver organização dos conceitos para armazená-los, com relações significativas entre eles, formando uma unidade, e os estudos sobre modelos conceituais auxiliam nessa organização. Portanto, faz-se necessário saber que:

[...] um modelo conceitual é uma ferramenta de organização da informação, capaz de representar ideias ou conceitos na forma de um diagrama hierárquico escrito ou gráfico e capaz de indicar as relações entre os conceitos, procurando refletir a organização da estrutura cognitiva sobre um determinado assunto. (LIMA, 2004c apud GARCIA, 2007). 
São considerados nos modelos de busca e recuperação da informação:

- Tesauro convencional: instrumento de indexação que não opera com o significado dos conceitos, agindo apenas como ferramenta de manipulação (representação, busca e recuperação) de documentos.

- Tesauro facetado: instrumento de indexação com estruturas hierárquicas de classificação independentes, possibilitando a captura por diferentes propriedades dos documentos, inclusive seus aspectos mais relevantes.

- Sistema conceitual de indexação: extensão da estrutura dos tesauros, porém composto por uma série de conceitos que têm a cada par um conceito comum.

- Hiperíndice semântico: instrumento de indexação em que "os conteúdos dos documentos são representados por um 'conjunto de termos de indexação' formado a partir do próprio documento, com os termos de indexação vinculados entre si” (GARCIA, 2007, p. 70).

- Rede de referência: formada por uma rede representativa de documentos e outra rede de perguntas demandadas pelo usuário, que são confrontadas durante o processo de busca.

- Rede semântica: possui estrutura semelhante à de uma rede hipertextual, porém sua organização é mais rica e suporta diferentes mecanismos de dedução.

- Ontologia: descreve conceitos e suas associações em um agente de software da web, possui analogia com tesauros e classificações conceituais, pois estabelece relações entre os conceitos, com a diferença de permitir representar e argumentar conhecimentos certos e imutáveis mediante regras de inferência.

Os inúmeros sistemas de processamento da informação disponíveis contribuíram para o aumento das relações das informações e dos próprios sistemas em ambientes digitais, contudo, ainda é prescindível melhorar as ferramentas de atendimento às necessidades do usuário. Os documentos já estão interconectados, restando agora torná-los mais intuitivos para serem manipulados por humanos.

O Comportamento Informacional está diretamente relacionado ao comportamento humano na busca, coleta, recuperação, organização e uso da informação e, como todo modelo, pretende ser uma representação sob determinado ponto de vista. Logo, cada

\begin{tabular}{l|l|l|l|l|l|l}
\hline (C) Rev. digit. bibliotecon. cienc. inf. & Campinas, SP & v.13 & n.1 & p.120-137 & jan/abr. 2015 & ISSN 1678-765X \\
\hline
\end{tabular}


conteúdo depende da perspectiva abordada, sendo as principais: cognitiva, social, sociocognitiva e organizacional (CAREGNATO, 2003).

Há, basicamente, duas categorias para modelos de recuperação da informação: modelos semânticos (análise semântica e sintática para análise da linguagem natural) e modelos estatísticos (medidas estatísticas e comparação entre consulta e documento). Sem se estender a suas especificidades, estão entre os modelos mais comuns: boleano, booleano estendido, vetorial, probabilístico, difuso, de indexação semântica latente e de processamento de linguagem natural. Todos eles, em diferentes modos e medidas, estão presentes nos modelos de busca desenvolvidos ao longo das pesquisas e tentativas de aprimoramento da recuperação da informação.

Ao longo da história, os estudos realizados sobre o tema têm tido caráter mais quantitativo, não revelando muito os pontos relevantes para o desenvolvimento da teoria. Recentemente, isso tem mudado, e a preocupação com o usuário, as necessidades de informação do indivíduo e os múltiplos comportamentos de busca passaram a ser o foco central. Os modelos só passaram a emergir, de fato, quando as pesquisas tomaram caráter qualitativo, relacionadas ao comportamento humano.

A seguir, as principais características dos modelos de comportamento de busca apresentados por Wilson, Kuhlthau, Dervin, Ellis, e Ingwersen (apud GARCIA 2007):

- Modelo de comportamento de busca: modelo que tem como proposição que a necessidade da informação provém de uma necessidade básica anterior do indivíduo - seja fisiológica, cognitiva ou afetiva - e que este pode encontrar diferentes barreiras no decorrer de sua busca. As hipóteses, por sua vez, estão somente implícitas (Figura 1). (WILSON, 1981 apud GARCIA 2007). 


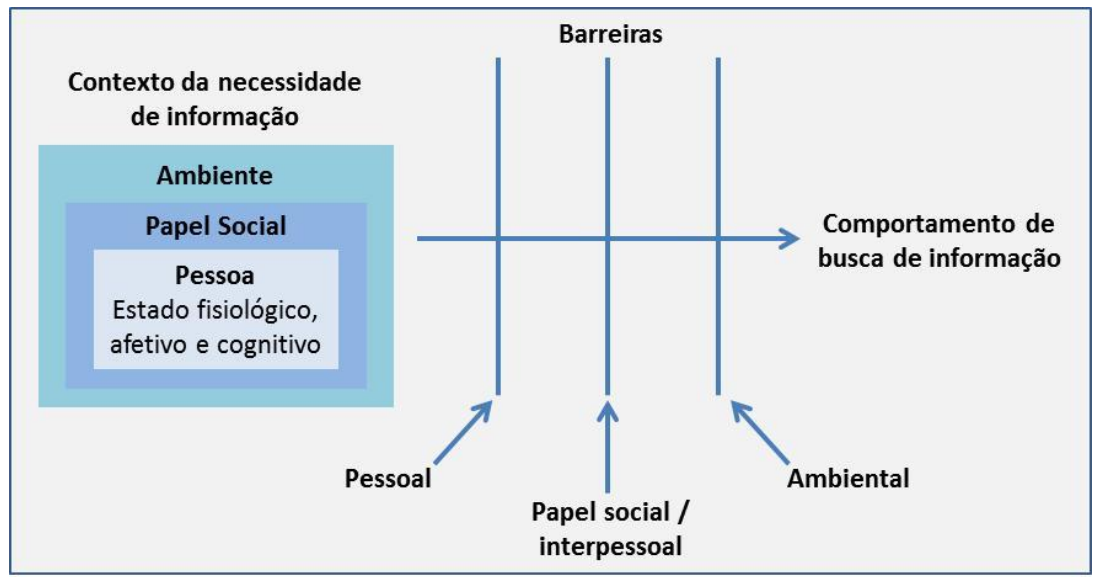

Figura 1 - Modelo de comportamento de busca

Fonte: Wilson (1981, apud GARCIA, 2007, p. 83).

- Modelo geral de comportamento de busca: neste modelo revisado é apresentado um ciclo de atividades de informação, com ativadores, interferências e influências significantes nos diferentes comportamentos informacionais e teorias de motivação por trás de cada comportamento de busca. O usuário em foco tem uma necessidade que precisa ser sanada, porém há várias intervenções que afetam os mecanismos e ativam o comportamento de busca (Figura 2). (WILSON, 1996 apud GARCIA, 2007).

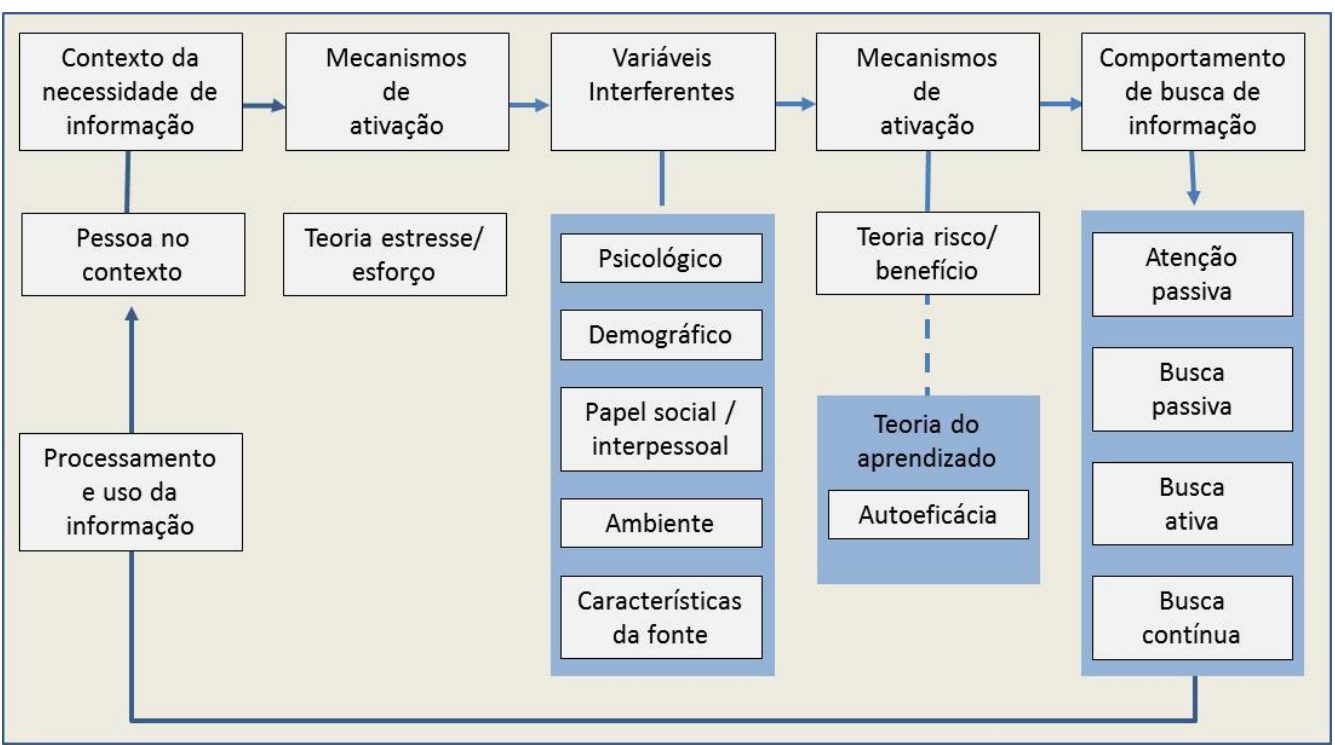

Figura 2 - Modelo geral comportamento de busca

Fonte: Wilson (1996 apud GARCIA, 2007, p. 85).

- Processo de busca da informação / Information Search Process (IPS): modelo que associa várias fases do processo de busca de informação aos sentimentos, pensamentos e ações do usuário, considerando o processo de 
construção da visão dos indivíduos a partir da assimilação da nova informação, ou seja, ele e sua bagagem de conhecimento (juntamente à cognição e sentimentos afetivos) constroem o significado da informação. Sua premissa é a incerteza, alterada com o estado de conhecimento, que faz aumentar o sentimento de confiança (Figura 3). (KUHLTHAU, 1993 apud GARCIA, 2007).

Divididos em seis etapas, os estágios são encadeados e respeitam uma ordem de ocorrência - uma hipótese de tal observação é a característica de um grupo primário em pesquisa (graduandos), com problemas básicos de informação.

- Início: há o reconhecimento da falta de conhecimento, não se sabe exatamente o que é preciso e os pensamentos são vagos - incerteza, apreensão e ansiedade.

- Seleção: fase de identificação e seleção dos tópicos gerais a serem investigados.

- Exploração: busca por informações relevantes a respeito de um tópico genérico confusão, incerteza e dúvida.

- Formulação: momento decisivo de direcionamento para o estudo - menos incerteza e mais confiança.

- Coleta: senso de direção definido e maior interação usuário-sistema - confiança.

- Apresentação: fase final do processo, em que são verificados os níveis de relevância e redundância das informações encontradas - alívio, satisfação ou descontentamento.

\begin{tabular}{|c|c|c|c|c|c|c|}
\hline Tarefas & Iniciação & Seleção & Exploração & Formulação & Coleção & Apresentação \\
\hline $\begin{array}{l}\text { Sentimentos } \\
\text { (afetivo) }\end{array}$ & Incerteza & Otimismo & $\begin{array}{l}\text { Confusão } \\
\text { Frustração } \\
\text { Dúvida }\end{array}$ & Clareza & $\begin{array}{l}\text { Senso de } \\
\text { direção, } \\
\text { confiança }\end{array}$ & $\begin{array}{c}\text { Satisfação } \\
\text { ou } \\
\text { Desapontamento }\end{array}$ \\
\hline $\begin{array}{l}\text { Pensamentos } \\
\text { (cognitivo) }\end{array}$ & \multicolumn{6}{|c|}{ Vago $\longrightarrow$ Focado } \\
\hline $\begin{array}{l}\text { Ações } \\
\text { (físico) }\end{array}$ & \multicolumn{3}{|c|}{$\begin{array}{l}\text { Busca pertinente de informação, } \\
\text { explorando }\end{array}$} & \multicolumn{3}{|c|}{$\begin{array}{l}\text { Busca pertinente de informação, } \\
\text { documentando }\end{array}$} \\
\hline
\end{tabular}

Figura 3 - Processo de Busca da Informação

Fonte: KUHLTHAU, 1993 apud GARCIA, 2007

- Sense-Making: modelo mais voltado ao usuário que à busca, pois considera haver diferentes comportamentos e contextos dos indivíduos, mesmo que estes 
estejam inseridos no mesmo ambiente e com interesses comuns. Ele considera uma situação, uma lacuna (incerteza), um resultado e uma ponte (entre a situação e o resultado). Ou seja, a necessidade da informação se insere na percepção de uma lacuna do conhecimento a ser sanada. Existe, portanto, um desconforto cognitivo perante a um problema (Figura 4). (DERVIN, 1986 apud GARCIA 2007).

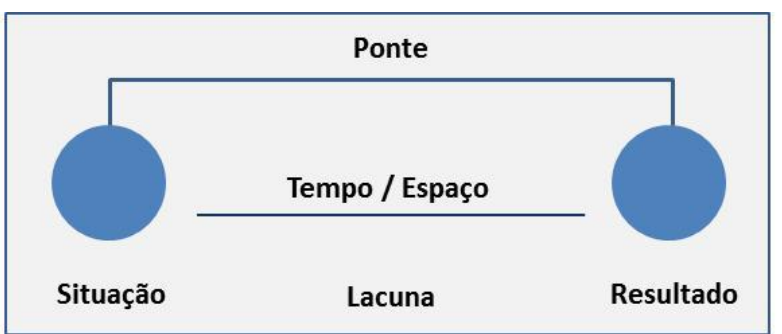

Figura 4 - Estrutura Sense-Making

Fonte: Dervin (1986 apud GARCIA, 2007, p. 102).

- Modelo comportamental de busca da informação: modelo sem forma, não diagramático, voltado à abordagem de grupos de cientistas sociais dos departamentos da Universidade de Sheffield, com o objeto de propor um novo desenho de sistemas de recuperação da informação, gerando modelos a partir de padrões individuais de acordo com características definidas em iniciação (meios de busca), ligação (conexão referencial entre os materiais), navegação (procura casual), diferenciação (filtro da informação), monitoramento (seguimento de fontes), extração (seleção de documentos), verificação (checagem) e finalização (busca final). Existe uma inter-relação dessas características que depende das circunstâncias das atividades de busca do usuário e elas são mais bem definidas em seis etapas (Figura 5). (ELLIS, 1989 apud GARCIA, 2007):

- Iniciar: atividades que definem o começo da busca por informação e permitem uma visão geral do que será estudado, descobrindo informações que podem servir de base para uma ampliação posterior da busca - conversas, literatura de revisão, catálogos e índices -, situação relacionada à experiência e ao conhecimento prévio do assunto pelo pesquisador.

- Encadear: contato com citações que levam a outras fontes, criando conexões entre o que foi pesquisado e as novas informações. 
- Navegar: busca semidirecionada a uma área de interesse geral - lista de autores, periódicos, anais etc.

- Diferenciar: avaliação do material levantado por meio de comparação das fontes.

- Monitorar: verificação do desenvolvimento da pesquisa por meio do monitoramento das fontes de informação específicas.

- Extrair: trabalho sistemático em determinada fonte para extração de material de interesse.

Embora possam ser vistas como unificadas, as sequências podem variar. Uma hipótese de tal observação é a característica de um grupo maduro em pesquisa (cientistas), com comprometimento permanente com os estudos.

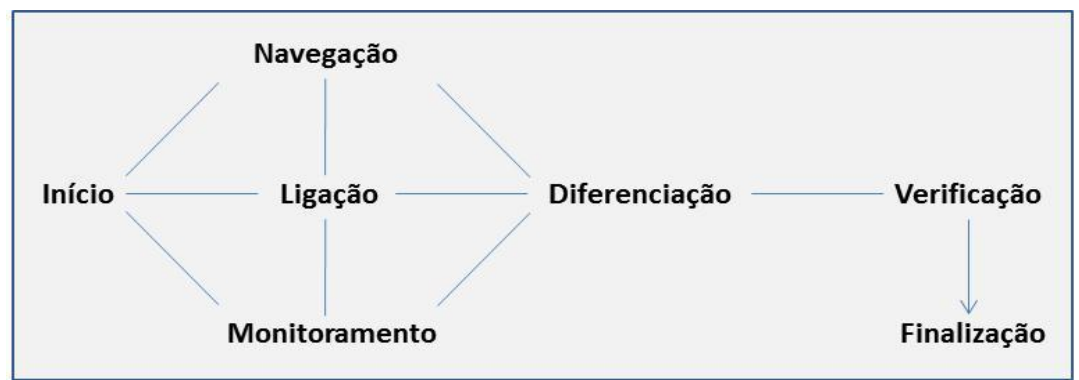

Figura 5 - Versão do processo de fases da estrutura comportamental de Ellis (1989)

Fonte: Wilson (1999 apud GARCIA, 2007, p. 107).

- Modelo cognitivo do processo de recuperação da informação: modelo focado em identificar os processos de cognição nos elementos de processamento da informação. As funções de cada agente da informação - usuário, autor do documento, intermediário, interface e sistema - são resultados dos modelos cognitivos do domínio de interesses particulares, que interagem e influenciam uns aos outros (Figura 6). (INGWERSEN, 2002 apud GARCIA 2007). 


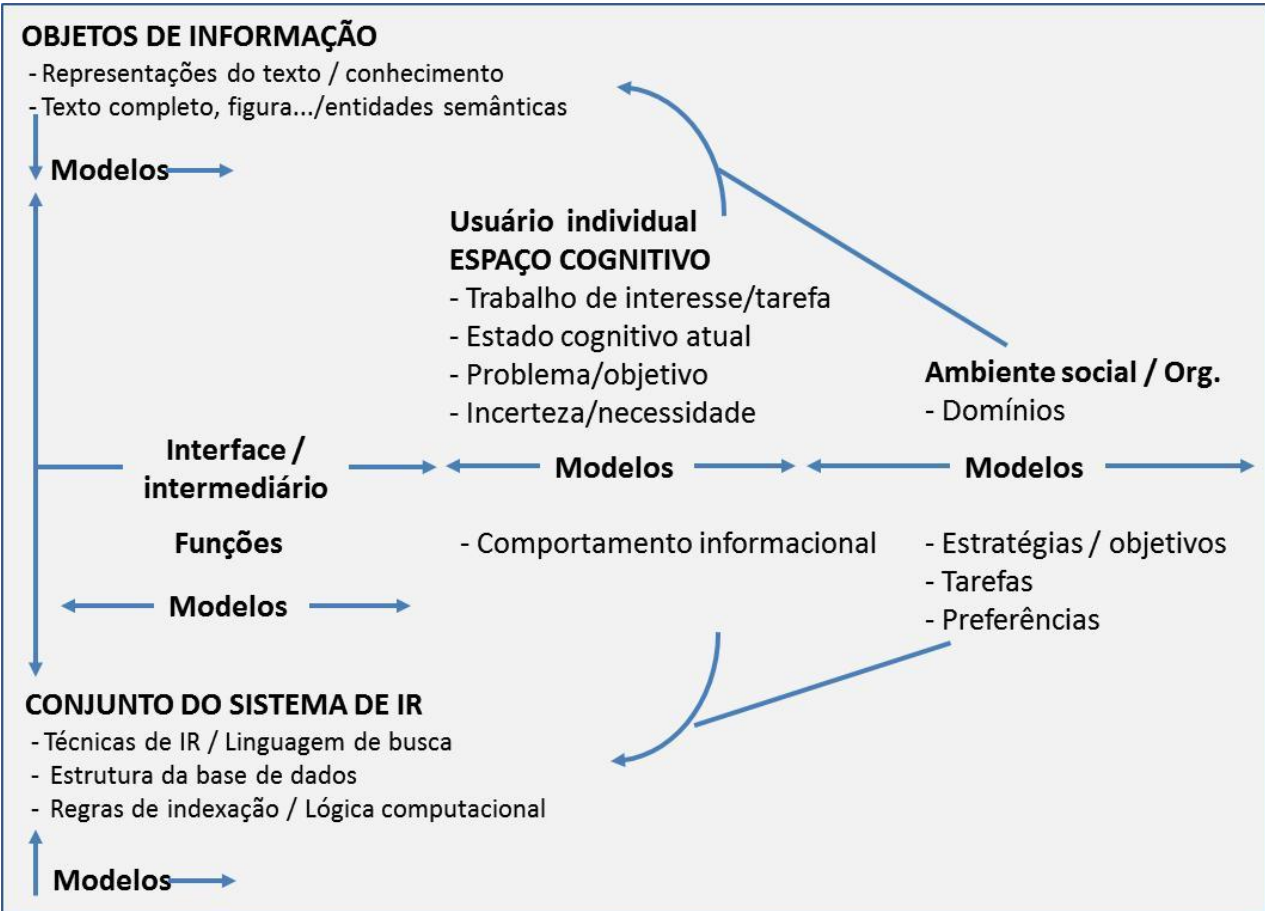

Figura 6 - Modelo cognitivo do processo de recuperação da informação (adaptado) Fonte: Wilson (1999); Ingwersen (2002) (apud GARCIA, 2007, p. 109).

\section{CONCLUSÃO}

Com os modelos apresentados, concentrados no modo de busca de informação e desenvolvidos a partir da mesma abordagem - o usuário -, percebe-se que as representações a serem elaboradas pelos profissionais da informação necessitam considerar o contexto específico do usuário, fazendo-se valer de linguagens documentárias diversificadas e com maior qualidade, focando-se no conceito de organização e recuperação da informação, pois somente assim será possível mais precisão e competência nos resultados finais alcançados. Embora Kuhlthau e Ellis direcionem seus estudos no comportamento de busca e Wilson, Ingwersen e Dervin explorem mais o contexto, ambos os modelos são complementares, uma vez que a observação dos comportamentos e suas motivações tornam possível o desenvolvimento de sistemas de organização e representação da informação, que promovam abordagens que facilitem o comportamento humano de busca.

Torna-se evidente, na Sociedade da Informação, a crescente relevância do investimento em pesquisas e abordagens que considerem o contexto contemporâneo, pois é este que define as necessidades, as competências a serem aprimoradas e as lacunas e falhas a serem modificadas. Nesse sentido, a questão é colocada em outro patamar, uma vez que 
interfere e influencia social e economicamente um país. A partir do momento em que a informação passa a adquirir valor econômico, saber utilizá-la e transformá-la em conhecimento é sinônimo de poder, pois somente o conhecimento aplicado pode desenvolver novos recursos e alavancar a economia.

As mudanças ocasionadas pela tecnologia usada para gerar, distribuir, acessar e usar a informação demandam por habilidades e competências relacionadas ao acesso, uso e disseminação da informação. É neste ponto que surge um novo usuário da informação com novas demandas por recursos computacionais e novas capacidades em produzir novos conhecimentos. Resulta desse procedimento que atualmente se conhece muita coisa sobre planejamento, aquisição, organização, controle e desenvolvimento de coleções, mas muito pouco sobre como as pessoas fazem uso dos sistemas ou para que fins, e como a informação, que é a matéria-prima do sistema, está sendo utilizada. Torna-se evidente a necessidade de aprofundar os estudos e pesquisas que permitam entender os modelos de busca e apropriação da informação em um cenário dependente de recursos computacionais na Web inteligente.

\section{REFERÊNCIAS}

BEPPLER, Fabiano Duarte. Um modelo para recuperação e busca de informação baseado em ontologia e no círculo hermenêutico. 135 f. (Tese) Doutorado em Engenharia e Gestão do Conhecimento. Universidade Federal de Santa Catarina, Florianópolis, 2008.

CAREGNATO, Sônia Elisa; CRESPO, Isabel Merlo. Comportamento de busca de informação: uma comparação de dois modelos. Em Questão. Porto Alegre, v. 9, n. 2, p. 271-281, jul./dez., 2003.

GARCIA, Rodrigo Moreira. Modelos de comportamento de busca de informação: contribuições para a organização da informação. 140 f. (Dissertação) Mestrado em Ciência da Informação. Faculdade de Filosofia e Ciências da Universidade Estadual Paulista, São Paulo, 2007.

LOPES, Ilza Leite. Estratégia de busca na recuperação da informação: revisão da literatura. Ciências da Informação. Brasília, v. 31, n. 2, p. 60-71, maio/ago., 2002. 
SQUIRRA, S. Sociedade do conhecimento. In: MARQUES DE MELO, J. M.; SATHLER, L. Direitos à Comunicação na Sociedade da Informação. São Bernardo do Campo, SP: Umesp, 2005.

TAKAHASHI, Tadao (org.). A sociedade da informação. In: Sociedade da informação no Brasil: Livro Verde. Brasília: Ministério da Ciência e Tecnologia, 2000, p. $1-14$.

\section{Como citar este artigo:}

PALETTA, Francisco Carlos; PELISSARO, Bárbara. Estudo de usuários e modelos de busca da informação. Rev. digit. bibliotecon. cienc. inf., Campinas, SP, v.13, n.1, p.120-137, jan/abr. 2015. ISSN 1678-765X. Disponível em: <http://www.sbu.unicamp.br/seer/ojs/index.php/rbci>. Acesso em: 31 Jan. 2015. 